\title{
PERHITUNGAN BEBAN RANCANGAN (DESIGN LOAD) KONSTRUKSI KAPAL BARANG UMUM 12.000 DWT BERBAHAN BAJA MENURUT REGULASI KELAS
}

\author{
Iswadi Nur \\ Program Studi Teknik Perkapalan, Fakultas Teknik, UPN Veteran Jakarta, Jakarta Selatan, Indonesia \\ iswadi.tp@gmail.com
}

\begin{abstract}
The ship's design load to be affected by some factors such as; the inside force of ship, the outside force of ship, the kind of ship, the ship's length, the comparison of ship's dimension, the sea water waves, and the corrosion of steel. The design load of ship's weather deck area $\left(P_{D}\right)$, the design load of ship's bottom area $\left(P_{B}\right)$, although the design load of ship's side area $\left(P_{S}\right)$ becomes parameter factor to calculate the ship's construction. The subject of design load calculation is the general cargo ships with main dimension as : Loa $=131,273 \mathrm{~m}$, Lpp $=122$, $360 \mathrm{~m}, \mathrm{~B}=19,50 \mathrm{~m}, \mathrm{H}=11,138 \mathrm{~m}, \mathrm{~T}=8,77 \mathrm{~m}, \mathrm{Cb}=0,74, \mathrm{dwt}=12.000$ tons, displacement $=$ 15.875 tons, speed $=13$ knots, $C m=0,98, C w=0,83, M E=6.700 \mathrm{hp}$. The calculation of of ship's design load had many results such as : the design load of weather deck $\left(P_{D}\right)$ likes; the mean of $P_{D}=107,851 \mathrm{kN} / \mathrm{m}^{2}$, the $P_{D}$ of after peak area $=9,99 \%$ more than the $P_{D}$ of middle area, because the super structures likes; poop deck, bridge deck, navigation deck, and wheel house to be supported by the deck plate of after peak area. Also the $P_{D}$ of fore peak area $=64$, $00 \%$ more than the $P_{D}$ of middle area, because location of the deck plate of fore peak area to the fore castle deck although the windlass to be close to one another, of course the deck plate of fore peak area support both of them. The design load of ship's bottom area $\left(P_{B}\right)$ likes; the mean of $P_{B}=126,515 \mathrm{kN} / \mathrm{m}^{2}$, the $P_{B}$ of after peak area $=13,93 \%$ more than the $P_{B}$ of middle area, because location of the after peak bottom plate to the engine room, the propeller, although the rudder to be close to one another, of course the bottom plate of after peak area can absorb the main engine vibration, the propeller vibration, although the rudder vibration. The $P_{B}$ of fore peak area $=29,50 \%$ more than the $P_{B}$ of middle area, because part of the bottom plate of fore peak area becomes the stem plate, and then the stem plate to be striked by the sea water waves when the ship voyage on the sea.The design load of ship's side area $\left(P_{S}\right)$ likes; the mean of $P_{S}$ $=98,471 \mathrm{kN} / \mathrm{m}^{2}$, the $P_{S}$ of after peak area $=11,53 \%$ more than the $P_{S}$ of middle area, and the $P_{S}$ of fore peak area $=20,80 \%$ more than the $P_{S}$ of middle area. The reason of them to be same with $P_{D}$ although $P_{B}$ before. More over, the mean value of $P_{B}$ more than the value of $P_{D}$ althought $P_{S}$, the deferences value to be affected by the factor of steel corrosion and the factor of sea water wave. Also the mean $P_{S}$ value less than the mean value of $P_{B}$ althought $P_{D}$, the deferences value to be affected by distance of the ship's side plate to the ship's longitudinal netral axis to be close to one another.
\end{abstract}

Keywords : ship's construction, design load, general cargo.

\section{Pendahuluan}

Pada penelitian terdahulu dengan judul "Faktor-faktor yang mempengaruhi beban rancangan (design load) terkait dengan perhitungan konstruksi kapal niaga berbahan baja menurut regulasi klas", (Iswadi Nur, Bina Teknika edisi bulan Juni 2015, volume 11 nomor 1), menyimpulkan bahwa sistem konstruksi kapal baja harus dapat menahan terhadap gaya -gaya yang bekerja dari dalam kapal maupun gaya dari luar kapal. Gaya dari dalam berhubungan dengan resultan gaya berat komponen kapal kosong (light weight) kapal maupun resultan gaya berat komponen bobot mati (dead weight) kapal. Sedangkan gaya yang berasal dari luar antara lain gelombang air laut dan tiupan angin yang menerpa badan kapal pada saat kapal berlayar.

Faktor-faktor yang dapat mempengaruhi beban rancangan (design load) dari perhitungan konstruksi kapal adalah; jenis kapal, jenis tumpuan beban pada lambung kapal, daerah pelayaran, perbandingan ukuran utama kapal, jenis baja, faktor korosi baja, 
konstanta yang berhubungan panjang kapal seperti konstanta daerah buritan kapal, konstanta daerah tengah kapal, serta konstanta daerah haluan kapal. Tahapan perancangan awal kapal adalah; penentuan ukuran utama, penentuan komponen dwt dan lwt, penentuan tahanan dan propulsi, penentuan stabilitas dan trim, rencana umum, bagan kapasitas dan gross tonnage, tahapan perancangan lanjut adalah; rencana garis, rencana umum dan spesikasi, hidrostatika, bonjean, konstruksi, kekuatan, tahanan dan propulsi, stabilitas dan trim.

Pada perhitungan perancangan kapal dalam pemilihan sistem konstruksi kapal atau. pemilihan sistem gading-gading kapal berdasarkan atas jenis dan ukuran utama kapal. Sistem konstruksi yang dipilih tersebuQ. harus dapat menahan dan kuat terhadap pengaruh gaya dari dalam kapal maupun pengaruh gaya dari luar kapal. Untuk pengaruh gaya dari dalam kapal adalah berat kapal kosong dan berat daya angkut, sedangkan untuk pengaruh gaya dari luar kapal adalah kondisi gelombang air laut (ombak) dan tiupan angin yang menerpa badan kapal pada saat berlayar. Secara teori pengaruh angin tidak terlalu diperhitungkan tetapi pengaruh gelombang air laut sangat diperhitungkan. Untuk pengaruh gelombang air laut dalam perhitungan konstruksi dan kekuatan bahwa kapal diasumsikan berada dalam 2 (dua) kondisi gelombang yang ekstrim yaitu pertama kapal berlayar pada kondisi satu puncak gelombang (hogging), letak kamar mesin berada di bagian tengah kapal, kedua kapal berlayar pada kondisi dua puncak gelombang (sagging), letak kamar mesin berada di buritan.

Pada penelitian kali ini dijelaskan beberapa faktor-faktor yang akan mempengaruhi perhitungan konstruksi kapal dalam hal penentuan beban rancangan (design load) pada kapal niaga berbahan baja beradasarkan Biro Klasifikasi Indonesia, dimana pada perhitungan beban rancangan dipilih adalah kapal barang umum 12.000 ton. Perhitungan beban rancangan (design load) konstruksi kapal barang umum berbahan baja menurut regulasi kelas tersebut dimaksudkan untuk mengetahui faktor-faktor yang mempengaruhi perbedaan perhitungan beban rancangan sepanjang kapal antara daerah buritan, daerah tengah, serta daerah haluan kapal. Metode penilaian adalah memperbandingkan besarnya (persentase) beban rancangan (design load) yang paling tinggi terhadap besarnya beban rangcangan yang paling rendah, selanjutnya dijelaskan faktor yang menyebabkan perbedaan antara keduanya.

\section{Tujuan}

Untuk mengetahui perhitungan beban rancangan (design load) konstruksi kapal barang umum $12.000 \mathrm{dwt}$ berbahan baja berdasarkan regulasi BKI.

Untuk mengetahui faktor-faktor yang mempengaruhi perhitungan beban rancangan (design load) konstruksi kapal berbahan baja.

Untuk memberikan materi pembelajaran mahasiswa pada mata kuliah Perancangan Kapal II.

\section{Perumusan Masalah}

Perhitungan beban rancangan (design load) konstruksi kapal barang umum 12.000 dwt berbahan baja menurut regulasi kelas dimaksudkan untuk mengetahui faktor-faktor yang mempengaruhi perbedaan hasil perhitungan beban rancangan sepanjang kapal antara daerah buritan, daerah tengah, serta daerah haluan kapal.

\section{Metode Penelitian}

Metode penilaian adalah memperbandingkan besarnya (persentase) beban rancangan (design load) yang paling tinggi terhadap besarnya beban rangcangan (design load) yang paling rendah, selanjutnya dijelaskan faktor yang menyebabkan perbedaan antara keduanya.

\section{Tinjauan Pustaka atau Acuan Perhitungan}

Pada bagian pendahuluan telah
disebutkan beberapa faktor yang mempengaruhi perhitungan beban rancangan kapal berbahan baja, salah satunya adalah nilai perbandingan ukuran utama. Untuk menjelaskan nilai perbandingan ukuran utama sesuai dengan parameter besar dan kecilnya kapal adalah sebagai berikut: 
Tabel 1. Perbandingan Ukuran Utama

\begin{tabular}{|c|l|c|c|c|c|c|}
\hline NO. & \multicolumn{1}{|c|}{\begin{tabular}{c}
\multicolumn{1}{|c|}{ TIPE } \\
KAPAL
\end{tabular}} & $\begin{array}{c}\text { HARGA } \\
\text { L/B }\end{array}$ & $\begin{array}{c}\text { HARGA } \\
\text { T/B }\end{array}$ & $\begin{array}{c}\text { HARGA } \\
\text { B/H }\end{array}$ & $\begin{array}{c}\text { HARGA } \\
\text { T/H }\end{array}$ & $\begin{array}{c}\text { HARGA } \\
\text { L/H }\end{array}$ \\
\hline 1. & $\begin{array}{l}\text { Kapal Cepat Besar } \\
\text { Vd=22 knots }\end{array}$ & $8,50-9,90$ & $0.37-0,43$ & $1,45-1,55$ & $0,58-0,66$ & $12,80-14,90$ \\
\hline 2. & $\begin{array}{l}\text { Kapal Barang Besar } \\
\text { Vd=15-18 knots }\end{array}$ & $8,90-9,00$ & $0,40-0,50$ & $1,50-1,70$ & $0,64-0,80$ & $13,30-15,00$ \\
\hline 3. & $\begin{array}{l}\text { Kapal Barang Besar } \\
\text { Vd=10 -15 knots }\end{array}$ & $7,00-8,50$ & $0,40-0,50$ & $1,50-1,80$ & $0,66-0,82$ & $11,60-14,00$ \\
\hline 4. & Kapal Sedang & $6,00-8,00$ & $0,40-0,50$ & $1,55-2,20$ & $0,70-0,99$ & $11,00-15,40$ \\
\hline 5. & $\begin{array}{l}\text { Kapal Cepat Jarak Pendek. } \\
\text { Vd=16-23 knots }\end{array}$ & $7,50-8,50$ & $0,25-0,35$ & $1,60-1,70$ & $0,41-0,58$ & $12,40-14,00$ \\
\hline 6. & Kapal Ikan & $5,00-6,00$ & $0,45-0,48$ & $1,60-1,80$ & $0,74-0,84$ & $8,50-10,00$ \\
\hline 7. & Kapal Tunda Samudra & $4,50-6,00$ & $0,37-0,47$ & $1,65-1,85$ & $0,65-0,82$ & $7,90-10,50$ \\
\hline 8. & Kapal Tunda Pelabuhan & $3,50-5,50$ & $0,37-0,46$ & $1,73-2,20$ & $0,73-0,90$ & $7,80-10,00$ \\
\hline 9. & Kapal-kapal Kecil & $6,00-8,50$ & $0,35-0,45$ & $1,50-1,70$ & $0,56-0,72$ & $9,60-13,60$ \\
\hline 10. & Kapal-kapal Motor Kecil (Layar) & $3,20-6,30$ & $0,30-0,50$ & ------- & $0,60-0,80$ & $6,00-11,00$ \\
\hline
\end{tabular}

Sumber : Teori Bangunan Kapal, I Gusti Made Santoso dkk.

\section{Konstanta Panjang Kapal $\left(\mathbf{C}_{\mathrm{D}}\right)$}

Tabel konstanta panjang kapal $\left(\mathrm{C}_{\mathrm{D}}\right)$ juga termasuk faktor yang mempengaruhi perhitungan beban rancangan konstruksi kapal, konstanta tersebut adalah sebagai berikut:

Tabael 2. Tabel konstanta panjang kapal $\left(\mathrm{C}_{\mathrm{D}}\right)$

\begin{tabular}{|c|c|c|c|}
\hline \multicolumn{2}{|c|}{ Daerah } & Faktor $C_{D}$ & Faktor $\mathrm{C}_{\mathrm{F}}$ \\
\hline $\begin{array}{c}\text { Buritan } \\
\text { A }\end{array}$ & $0 \leq \frac{x}{L} \leq$ & $1,2-\frac{x}{L}$ & $\begin{array}{c}1,0+\frac{5}{C B}[0,2- \\
\left.\frac{x}{L}\right]\end{array}$ \\
\hline $\begin{array}{c}\text { Tengah } \\
\text { M }\end{array}$ & $\begin{array}{c}0,2 \leq \frac{x}{L} \leq \\
0,7\end{array}$ & 1,0 & 1,0 \\
\hline $\begin{array}{c}\text { Haluan } \\
\text { F }\end{array}$ & $\begin{array}{c}0,7 \leq \frac{x}{L} \leq \\
1,0\end{array}$ & $\begin{array}{l}1,0+\frac{c}{3}\left[\frac{x}{L}-0,7\right] \\
c=0,15 \mathrm{~L}-10 \\
\operatorname{dimana} \\
\mathrm{L}_{\min }=100 \mathrm{~m} \\
\mathrm{Lmax}=250 \mathrm{~m}\end{array}$ & $\begin{array}{c}1,0+\frac{20}{C B}\left[\frac{x}{L}-\right. \\
0,7]^{2}\end{array}$ \\
\hline
\end{tabular}

Di dalam daerah A rasio $\frac{x}{L}$ tidak perlu diambil kurang dari 0,1 , dan di dalam daerah $\mathrm{F}$ rasio $\frac{x}{L}$ tidak perlu diambil lebih besar dari 0,93

Sumber : Biro Klasifikasi Indonesia 2009

\section{Konstanta Tegangan Luluh Bahan Baja dan Korosi}

Dalam perhitungan konstruksi kapal berbahan baja yang dihubungkan dengan kekuatan memanjang kapal, maka diasumsikan bahwa kapal harus dapat menahan dua kondisi gelombang air laut yang ekstrim yaitu kapal berada dalam kondisi satu puncak gelombang (hogging) dan kapal berada dalam kondisi dua puncak gelombang (sagging), artinya konstruksi kapal dapat menahan tegangan yang terjadi pada badan kapal akibat gelombang tersebut di atas. Pada saat kondisi hogging pelat dasar daerah tengah kapal mengalami tegangan tekan, dan pelat geladak daerah tengah kapal mengalami tegangan tarik. Sebaliknya pada saat kondisi sagging pelat dasar mengalami tegangan tarik, dan pelat geladak mengalami tegangan tekan. Menurut regulasi klasifikasi Bab 2, Bagian B. 2 tentang baja konstruksi lambung kekuatan tinggi, halaman $2-1$, ditentukan dengan harga tegangan luluh dan faktor keamanan k, sebagai berikut:

Tabel 3. Faktor Bahan

\begin{tabular}{|c|c|}
\hline $\mathrm{ReH}(\mathrm{N} / \mathrm{mm} 2)$ & $\mathrm{k}$ \\
\hline 265 & 0,91 \\
\hline 315 & 0,78 \\
\hline 355 & 0,72 \\
\hline 390 & 0,66 \\
\hline
\end{tabular}

Sumber: Biro Klasifikasi Indonesia, 2004

Sedangkan untuk konstanta korosi dari bahan baja harus sesuai dengan Bab 3, Bagian K. 1, tentang marjin korosi $\left(t_{K}\right)$ tidak boleh kurang dari $\mathrm{t}_{\mathrm{K}}$ yang terdapat pada tabel 3.6, sebagai berikut:

Tabel 4. Marjin Korosi Minimum

\begin{tabular}{|l|c|}
\hline \multicolumn{1}{|c|}{ Daerah } & $\mathrm{t}_{\mathrm{K}} \min (\mathrm{mm})$ \\
\hline $\begin{array}{l}\text { Dalam tangki balas dimana geladak } \\
\text { cuaca menjadi atap tangki, 1,5 } \mathrm{m} \mathrm{di}\end{array}$ & 2,5 \\
bawah atap tangki 1$)$ & \\
\hline $\begin{array}{l}\text { Dalam tangki minyak muatan dimana } \\
\text { geladak cuaca menjadi atapnya, 1,5 m di }\end{array}$ & 2,0 \\
bawah atap tangki. Bagian horizontal \\
dalam tangki minyak muatan dan tangki \\
bahan bakar. \\
$\begin{array}{l}\text { Pelat geladak di bawah rumah geladak } \\
\text { yang dipasang secara elastis }\end{array}$ \\
\hline $\begin{array}{l}\mathrm{t}_{\mathrm{K}}=2,5 \text { untuk semua konstruksi di dalam tangki sayap atas } \\
\text { kapal curah. }\end{array}$ \\
\hline $\begin{array}{l}\text { Sekat bujur terbuka terhadap operasi cengkram dan diberi } \\
\text { notasi } \mathrm{G}, \text { maka marjin korosi } \mathrm{t}_{\mathrm{K}}=2,5 \mathrm{~mm} \text {. }\end{array}$ \\
Sumber: Biro Klasifikasi Indonesia, 2004
\end{tabular}

\section{Jenis Kapal}


Jenis atau macam kapal juga dapat mempengaruhi perhitungan beban rancangan akibat dari bentuk rencana umum dan sistem konstruksinya, adapun jenis kapal dimaksud adalah sebagai berikut :

1. Kapal Penumpang.

2. Kapal Tambangan.

3. Kapal Tarik.

4. Kapal Dorong.

5. Kapal Tangki.

6. Kapal Muatan Curah.

7. Kapal Peti Kemas.

8. Kapal Barang Umum, dll

Berdasarkan pembagian jenis kapal tersebut pasti mempengaruhi perhitungan beban rancangannya karena masing-masing jenis kapal memiliki karakteristik yang berbeda antara jenis kapal satu dengan jenis kapal lainnya.

\section{Jenis Tumpuan Beban di Kapal}

Jenis balok tumpuan pada konstruksi kapal dipengaruhi oleh bentuk dan sistem konstruksinya. Jenis balok tumpuan pada kapal tersebut hampir sama dengan jenis tumpuan pada bangunan sipil, sehingga perlu mengetahui jenis balok tumpuannya untuk mempermudah dalam perhitungan beban rancangan konstruksi kapal, terdapat beberapa jenis tumpuan yang dikenal, antara lain;
a. Rol (Penghubung)
b. Pasak (Pin).
c. Tumpuan Jepit
d. Balok dengan tumpuan sederhana
e. Balok Jepit
f. Balok Kantilever.
g. Balok Tergantung/Overhanged
h. Balok Kontinyu.

\section{Pembahasan:}

Dipilih Kapal Barang Umum dengan ukuran utama (main dimension) sebagai berikut:

Tabel 5. Main Dimension

\begin{tabular}{|l|r|}
\hline \multicolumn{1}{|c|}{ Main Dimension } & \multicolumn{1}{c|}{ Satuan } \\
\hline Loa & $131,273 \mathrm{~m}$ \\
\hline Lpp & $122,360 \mathrm{~m}$ \\
\hline B & $19,500 \mathrm{~m}$ \\
\hline $\mathrm{D}(\mathrm{H})$ & $11,138 \mathrm{~m}$ \\
\hline $\mathrm{T}(\mathrm{d})$ & $8,770 \mathrm{~m}$ \\
\hline $\mathrm{Cb}$ & 0,740 \\
\hline $\mathrm{DWT}$ & $12.000,00 \mathrm{ton}$ \\
\hline$\Delta$ & $15.875,02 \mathrm{ton}$ \\
\hline $\mathrm{Vd}$ & $13,650 \mathrm{knots}$ \\
\hline $\mathrm{Vp}$ & $14,742 \mathrm{knots}$ \\
\hline $\mathrm{ME}$ & $6700 \mathrm{hp}$ \\
\hline $\mathrm{Cm}$ & 0,98 \\
\hline
\end{tabular}

\begin{tabular}{|l|r|}
\hline $\mathrm{Cw}$ & 0,83 \\
\hline $\mathrm{Cp}$ & 0,7551 \\
\hline
\end{tabular}

Sumber : Data skripsi mahasiswa Teknik Perkapalan

Beban rancangan (design load) yang dihitung adalah :

a. Beban geladak cuaca

b. Beban pada dasar (alas) kapal.

c. Beban pada sisi kapal.

\section{Hasil Perhitungan:}

a. Beban rancangan pada geladak cuaca $\left(\mathbf{P}_{\mathrm{D}}\right)$, Bab 4

Rumus beban rancangan adalah:

$\mathrm{P}_{\mathrm{D}}=\mathrm{P}_{\mathrm{O}} \frac{20 T}{(10+z-T) H} C D\left\{\mathrm{kN} / \mathrm{m}^{2}\right\}$

Konstanta $\mathrm{C}_{\mathrm{D}}$ adalah konstanta daerah buritan, konstanta daerah tengah kapal, dan konstanta daerah haluan kapal.

$\mathrm{C}_{\mathrm{D}}=1,2-\frac{x}{L}$; untuk daerah A (after peak = buritan kapal) sesuai tabel 4.1

$\mathrm{C}_{\mathrm{D}}=1,2-0,10-------\rightarrow \frac{x}{L}=0,10$

$\mathrm{C}_{\mathrm{D}}=1,1$

$\mathrm{C}_{\mathrm{D}}=1,0$; untuk daerah $\mathrm{M}$ (middle ship $=$ tengah kapal)

$\mathrm{C}_{\mathrm{D}}=1,0+\frac{C}{3}\left(\frac{x}{L}-0,7\right) ;$ untuk daerah $\mathrm{F}$ (fore peak $=$ haluan kapal)

$\mathrm{C}=0,15 \mathrm{~L}-10$

$\mathrm{C}=0,15 \times 122,360-10=18,354-10=$ 8,354

$\mathrm{C}_{\mathrm{D}}=1,0+\frac{8,354}{3}(0,93-0,7) \ldots \ldots \ldots>\frac{x}{L}$

$=0,93$

$\mathrm{C}_{\mathrm{D}}=1,0+0,640$

$\mathrm{C}_{\mathrm{D}}=1,640$

$P_{O}=2,1\left(C_{B}+0,7\right) \times C_{O} \times C_{L} \times f \times C_{W R}$ $\left(\mathrm{kN} / \mathrm{m}^{2}\right)$, sesuai Bab 4 A. 2.2.

Dimana:

$\mathrm{C}_{\mathrm{B}}=$ koefisien blok kapal $=0,74$

$\mathrm{C}_{\mathrm{O}}=$ koefisien gelombang

$\mathrm{C}_{\mathrm{O}}=10,75-\left\{\frac{300-L}{100}\right\}^{1.5}$ untuk $90 \mathrm{~m} \leq \mathrm{L} \leq$ $300 \mathrm{~m}$

$\mathrm{L}=\mathrm{Lpp}=122,36 \mathrm{~m}$

$\mathrm{C}_{\mathrm{O}}=10,75-\left\{\frac{300-L}{100}\right\}^{1.5}$

$\mathrm{C}_{\mathrm{O}}=10,75-\left\{\frac{300-122,36}{100}\right\}^{1.5}$

$\mathrm{C}_{\mathrm{O}}=10,75-2,367=8,383$

$\mathrm{C}_{\mathrm{L}}=1,0$ untuk $\mathrm{L} \geq 90 \mathrm{~m}$ sesuai $\mathrm{Bab}$ 4.A.2.2. 
$\mathrm{C}_{\mathrm{WR}}=1,00$ untuk daerah pelayaran Tak

Terbatas

$\mathrm{C}_{\mathrm{WR}}=0,90$ untuk daerah pelayaran $\mathrm{P}$ (Samudera Terbatas)

$\mathrm{C}_{\mathrm{WR}}=0,75$ untuk daerah pelayaran $\mathrm{L}$ (Lokal)

$\mathrm{C}_{\mathrm{WR}}=0,60$ untuk daerah pelayaran $\mathrm{T}$ (Tenang)

$\mathrm{f}=$ faktor peluang

$\mathrm{f}=1,0$ untuk panel pelat lambung luar (pelat kulit, geladak cuaca)

$\mathrm{f}=0,75$ untuk bagian penguat sekunder lambung luar (gading-gading, balok geladak) tetapi tidak kurang $\mathrm{f}_{\mathrm{Q}}$, sesuai Bab 5. D.1

$\mathrm{f}=0,60$ untuk penumpu dan sistem penumpu lambung luar (gading besar, senta, sisten kisi) tetapi tidak kurang dari $\mathrm{f}_{\mathrm{Q}} / 1,25$.

$\mathrm{P}_{\mathrm{O}}=2,1(0,74+0,7) \times 8,383 \times 1,0 \times 1,0 \times$ $0,90\left(\mathrm{kN} / \mathrm{m}^{2}\right)$

$\mathrm{P}_{\mathrm{O}}=22,815 \mathrm{kN} / \mathrm{m}^{2}$

Beban rancangan geladak daerah buritan kapal (After Peak $=A)$ :

$\mathrm{P}_{\mathrm{D}}=\mathrm{P}_{\mathrm{O}} \quad \frac{20 T}{(10+z-T) H} C D \quad\left\{\mathrm{kN} / \mathrm{m}^{2}\right\}$, $>\mathrm{P}_{\mathrm{O}}=22,815$

Sarat air kapal $\mathrm{T}=8,770 \mathrm{~m}$

Jarak vertikal pusat beban konstruksi di atas garis dasar $Z=1 / 3 \times 8,77=2,923 \mathrm{~m}$ Maka :

Beban rancangan geladak daerah buritan kapal $($ After Peak $=\mathrm{A})$

$\mathrm{P}_{\mathrm{D}}=\mathrm{P}_{\mathrm{O}} \frac{20 T}{(10+z-T) H} C D\left\{\mathrm{kN} / \mathrm{m}^{2}\right\}$

$\mathrm{P}_{\mathrm{D}}=22,815 \times 3,7919 \times 1,1=95,163$ $\left\{\mathrm{kN} / \mathrm{m}^{2}\right\}$

Beban rancangan geladak daerah tengah kapal (Middle Ship $=\mathrm{M})$ :

$\mathrm{P}_{\mathrm{D}}=\mathrm{P}_{\mathrm{O}} \frac{20 T}{(10+z-T) H} C D\left\{\mathrm{kN} / \mathrm{m}^{2}\right\}$

$\mathrm{P}_{\mathrm{D}}=22,815 \times 3,7919 \times 1,0=86,51219$ $\left\{\mathrm{kN} / \mathrm{m}^{2}\right\}$

Beban rancangan geladak daerah haluan kapal $($ Fore Peak $=$ F):

$\mathrm{P}_{\mathrm{D}}=22,815 \frac{208,77}{(10+2,923-8,77) 11,138} \times 1,640$ $\left\{\mathrm{kN} / \mathrm{m}^{2}\right\}$

$\mathrm{P}_{\mathrm{D}}=22,815 \times 3,7919 \times 1,640=141,880$ $\left\{\mathrm{kN} / \mathrm{m}^{2}\right\}$
Tabel 6. Perbedaan Beban Rancangan (Design Load) Geladak Kapal

\begin{tabular}{|c|c|c|c|}
\hline No. & $\begin{array}{c}\text { Faktor } \mathrm{C}_{\mathrm{D}} ; \\
\text { Daerah } \\
\text { Sepanjang Kapal }\end{array}$ & $\begin{array}{c}\text { Beban } \\
\text { Rancangan } \\
\text { Geladak Kapal } \\
\left(\mathrm{P}_{\mathrm{D}}\right)\left\{\mathrm{kN} / \mathrm{m}^{2}\right\}\end{array}$ & $\begin{array}{c}\text { Perbedaan } \\
\text { Dihitung } \\
\text { Dari } \\
\text { Daerah } \\
\text { Tengah } \\
\text { Kapal }\end{array}$ \\
\hline 1. & $\begin{array}{l}\text { Beban } \\
\text { rancangan } \\
\text { geladak daerah } \\
\text { buritan kapal }(\mathrm{A}) \\
\mathrm{P}_{\mathrm{D}}=\left\{\mathrm{kN} / \mathrm{m}^{2}\right\}\end{array}$ & 95,163 & $\begin{array}{c}8,651= \\
9,999 \% \\
\text { lebih besar } \\
\text { dari } \mathrm{P}_{\mathrm{D}} \\
\text { tengah } \\
\text { kapal }\end{array}$ \\
\hline 2. & $\begin{array}{l}\text { Beban } \\
\text { rancangan } \\
\text { geladak daerah } \\
\text { tengah kapal }(\mathrm{M}) \\
\mathrm{P}_{\mathrm{D}}=\left\{\mathrm{kN} / \mathrm{m}^{2}\right\}\end{array}$ & 86,512 & 0 \\
\hline 3. & $\begin{array}{l}\text { Beban } \\
\text { rancangan } \\
\text { geladak daerah } \\
\text { haluan kapal }(\mathrm{F}) \\
\mathrm{P}_{\mathrm{D}}=\left\{\mathrm{kN} / \mathrm{m}^{2}\right\}\end{array}$ & 141,880 & $\begin{array}{c}55,368= \\
64,00 \% \\
\text { lebih besar } \\
\text { dari } \mathrm{P}_{\mathrm{D}} \\
\text { tengah } \\
\text { kapal }\end{array}$ \\
\hline 4. & Rata-rata $\mathrm{P}_{\mathrm{D}}$ & $\Sigma=323,555$ & $\begin{array}{c}\sum / 3= \\
107,851\end{array}$ \\
\hline
\end{tabular}

b. Beban rancangan dasar kapal

$\mathrm{P}_{\mathrm{B}}=10 \mathrm{~T}+\mathrm{P}_{\mathrm{O}} \mathrm{C}_{\mathrm{F}}\left\{\mathrm{kN} / \mathrm{m}^{2}\right\}$

Dimana $P_{O}=22,815\left\{\mathrm{kN} / \mathrm{m}^{2}\right\}$

$\mathrm{C}_{\mathrm{F}}$ sesuai tabel 4.1 adalah konstanta daerah buritan, konstanta daerah tengah kapal, dan konstanta daerah haluan (sama dengan sisi kapal).

Daerah buritan kapal (After Peak $=\mathrm{A})$ $\mathrm{C}_{\mathrm{F}}=1,0+\frac{5}{C B}\left(0,2-\frac{x}{L}\right)$, dimana $\frac{x}{L}=0,10$

$\mathrm{C}_{\mathrm{F}}=1,0+\frac{5}{0,74}(0,2-0,10)=1,0+0,675$ $=1,675$

Daerah tengah kapal (Middle Ship $=\mathrm{M})$ :

$\mathrm{C}_{\mathrm{F}}=1,0$

Daerah haluan kapal (Fore Peak $=$ F):

$\mathrm{C}_{\mathrm{F}}=1,0+\frac{20}{C B}\left(\frac{x}{L}-0,7\right)^{2}$, dimana $\frac{x}{L}=$ 0,93

$\mathrm{C}_{\mathrm{F}}=1,0+\frac{20}{0,74}(0,93-0,7)^{2}=1,0+1,429$

$=2,429$, maka:

Beban rancangan dasar daerah buritan kapal (A)

$\mathrm{P}_{\mathrm{B}}=10 \mathrm{~T}+\mathrm{P}_{\mathrm{O}} \mathrm{C}_{\mathrm{F}}\left\{\mathrm{kN} / \mathrm{m}^{2}\right\}$ 
$P_{B}=10 \times 8,77+22,815 \times 1,675\left\{\mathrm{kN} / \mathrm{m}^{2}\right\}$

$\mathrm{P}_{\mathrm{B}}=125,915 \quad\left\{\mathrm{kN} / \mathrm{m}^{2}\right\}$

\section{Beban rancangan dasar daerah tengah} kapal (M)

$\mathrm{P}_{\mathrm{B}}=10 \mathrm{~T}+\mathrm{P}_{\mathrm{O}} \mathrm{C}_{\mathrm{F}}\left\{\mathrm{kN} / \mathrm{m}^{2}\right\}$

$P_{B}=10 \times 8,77+22,815 \times 1,0\left\{\mathrm{kN} / \mathrm{m}^{2}\right\}$

$\mathrm{P}_{\mathrm{B}}=110,515 \quad\left\{\mathrm{kN} / \mathrm{m}^{2}\right\}$

Beban rancangan dasar daerah haluan kapal (F)

$\mathrm{P}_{\mathrm{B}}=10 \mathrm{~T}+\mathrm{P}_{\mathrm{O}} \mathrm{C}_{\mathrm{F}}\left\{\mathrm{kN} / \mathrm{m}^{2}\right\}$

$P_{B}=10 \times 8,77+22,815 \times 2,429\left\{\mathrm{kN} / \mathrm{m}^{2}\right\}$

$\mathrm{P}_{\mathrm{B}}=143,117\left\{\mathrm{kN} / \mathrm{m}^{2}\right\}$

Tabel 7. Perbedaan Beban Rancangan (Design Load) Dasar Kapal

\begin{tabular}{|c|c|c|c|}
\hline No. & $\begin{array}{c}\text { Konstanta } \mathrm{C}_{\mathrm{F}} \\
\text { Daerah } \\
\text { Sepanjang } \\
\text { Kapal }\end{array}$ & $\begin{array}{c}\text { Beban } \\
\text { Rancangan } \\
\text { Dasar Kapal } \\
\left(\mathrm{P}_{\mathrm{B}}\right) \\
\left\{\mathrm{kN} / \mathrm{m}^{2}\right\}\end{array}$ & $\begin{array}{l}\text { Perbedaan } \\
\text { Dihitung } \\
\text { Dari Daerah } \\
\text { Tengah } \\
\text { Kapal } \\
\end{array}$ \\
\hline 1. & $\begin{array}{l}\text { Beban } \\
\text { rancangan } \\
\text { geladak daerah } \\
\text { buritan kapal } \\
\text { (A) } \\
\mathrm{P}_{\mathrm{B}}=\left\{\mathrm{kN} / \mathrm{m}^{2}\right\}\end{array}$ & 125,915 & $\begin{array}{c}15,400= \\
13,934 \% \\
\text { lebih besar } \\
\text { dari } \mathrm{P}_{\mathrm{B}} \\
\text { tengah kapal }\end{array}$ \\
\hline 2. & $\begin{array}{l}\text { Beban } \\
\text { rancangan } \\
\text { geladak daerah } \\
\text { tengah kapal } \\
(\mathrm{M}) \\
\mathrm{P}_{\mathrm{B}}=\left\{\mathrm{kN} / \mathrm{m}^{2}\right\}\end{array}$ & 110,515 & 0 \\
\hline 3. & $\begin{array}{l}\text { Beban } \\
\text { rancangan } \\
\text { geladak daerah } \\
\text { haluan kapal }(\mathrm{F}) \\
\mathrm{P}_{\mathrm{B}}=\left\{\mathrm{kN} / \mathrm{m}^{2}\right\}\end{array}$ & 143,117 & $\begin{array}{c}32,602= \\
29,500 \% \\
\text { lebih besar } \\
\text { dari } \mathrm{P}_{\mathrm{B}} \\
\text { tengah kapal }\end{array}$ \\
\hline 4. & Rata-rata $\mathrm{P}_{\mathrm{B}}$ & $\sum=379,547$ & $\begin{array}{c}\sum / 3= \\
126,515\end{array}$ \\
\hline
\end{tabular}

\section{c. Beban rancangan sisi kapal}

$\mathrm{P}=\mathrm{P}_{\mathrm{S}}$ atau $\mathrm{Pe}$

$\mathrm{P}_{\mathrm{S}}=10(\mathrm{~T}-\mathrm{z})+\mathrm{P}_{\mathrm{O}} \cdot \mathrm{C}_{\mathrm{F}}\left(1+\frac{z}{T}\right)$, untuk arah gelombang yang searah atau berlawanan dengan arah maju kapal

Beban rancangan sisi daerah buritan kapal (A)

$\mathrm{P}_{\mathrm{S}}=10(\mathrm{~T}-\mathrm{z})+\mathrm{P}_{\mathrm{O}} \cdot \mathrm{C}_{\mathrm{F}}\left(1+\frac{z}{T}\right)\left\{\mathrm{kN} / \mathrm{m}^{2}\right\}$

$\mathrm{P}_{\mathrm{S}}=10(8,77-2,923)+22,815.1,675(1$

$\left.+\frac{2,923}{8,77}\right)\left\{\mathrm{kN} / \mathrm{m}^{2}\right\}$

$\mathrm{P}_{\mathrm{S}}=10$
$\mathrm{P}_{\mathrm{S}}=99,140\left\{\mathrm{kN} / \mathrm{m}^{2}\right\}$

Beban rancangan sisi daerah tengah kapal (M)

$\mathrm{P}_{\mathrm{S}}=10(\mathrm{~T}-\mathrm{z})+\mathrm{P}_{\mathrm{O}} \cdot \mathrm{C}_{\mathrm{F}}\left(1+\frac{z}{T}\right)\left\{\mathrm{kN} / \mathrm{m}^{2}\right\}$

$\mathrm{P}_{\mathrm{S}}=10(8,77-2,923)+22,815 \cdot 1,0(1+$

$\left.\frac{2,923}{8,77}\right)\left\{\mathrm{kN} / \mathrm{m}^{2}\right\}$

$\mathrm{P}_{\mathrm{S}}=88,889\left\{\mathrm{kN} / \mathrm{m}^{2}\right\}$

Beban rancangan sisi daerah haluan kapal (F)

$$
\begin{aligned}
& \mathrm{P}_{\mathrm{S}}=10(\mathrm{~T}-\mathrm{z})+\mathrm{P}_{\mathrm{O}} \cdot \mathrm{C}_{\mathrm{F}}\left(1+\frac{z}{T}\right)\left\{\mathrm{kN} / \mathrm{m}^{2}\right\} \\
& \mathrm{P}_{\mathrm{S}}=10(8,77-2,923)+22,815 \cdot(1+ \\
& \left.\frac{2,923}{8,77}\right)\left\{\mathrm{kN} / \mathrm{m}^{2}\right\} \\
& \quad \mathrm{P}_{\mathrm{S}}=107,383\left\{\mathrm{kN} / \mathrm{m}^{2}\right\}
\end{aligned}
$$

\begin{tabular}{|c|c|c|c|}
\hline No. & $\begin{array}{c}\text { konstanta } \mathrm{C}_{\mathrm{F}} ; \\
\text { Daerah Sepanjang } \\
\text { Kapal }\end{array}$ & $\begin{array}{c}\text { Beban } \\
\text { Rancangan } \\
\text { Dasar Kapal } \\
\left(\mathrm{P}_{\mathrm{S}}\right) \\
\left\{\mathrm{kN} / \mathrm{m}^{2}\right\}\end{array}$ & $\begin{array}{l}\text { Perbedaan } \\
\text { Dihitung } \\
\text { Dari Daerah } \\
\text { Tengah } \\
\text { Kapal }\end{array}$ \\
\hline 1. & $\begin{array}{l}\text { Beban rancangan } \\
\text { geladak daerah } \\
\text { buritan kapal }(\mathrm{A}) \\
\mathrm{P}_{\mathrm{S}}=\left\{\mathrm{kN} / \mathrm{m}^{2}\right\}\end{array}$ & 99,140 & $\begin{array}{c}10,251= \\
11,532 \% \\
\text { lebih besar } \\
\text { dari } \mathrm{P}_{\mathrm{S}} \\
\text { tengah kapal }\end{array}$ \\
\hline 2. & $\begin{array}{l}\text { Beban rancangan } \\
\text { geladak daerah } \\
\text { tengah kapal }(\mathrm{M}) \\
\mathrm{P}_{\mathrm{S}}=\left\{\mathrm{kN} / \mathrm{m}^{2}\right\}\end{array}$ & 88,889 & 0 \\
\hline 3. & $\begin{array}{l}\text { Beban rancangan } \\
\text { geladak daerah } \\
\text { haluan kapal }(\mathrm{F}) \\
\mathrm{P}_{\mathrm{S}}=\left\{\mathrm{kN} / \mathrm{m}^{2}\right\}\end{array}$ & 107,383 & $\begin{array}{c}18,494= \\
20,805 \% \\
\text { lebih besar } \\
\text { dari } \mathrm{P}_{\mathrm{S}} \\
\text { tengah kapal }\end{array}$ \\
\hline 4. & Rata-rata $P_{S}$ & $\sum=295,412$ & $\sum / 3=98,471$ \\
\hline
\end{tabular}

Tabel 8. Perbedaan Beban Rancangan (Design

\begin{tabular}{|c|c|c|c|}
\hline No. & $\begin{array}{c}\text { Konstanta } \\
\mathrm{C}_{\mathrm{D}}, \mathrm{C}_{\mathrm{F}} ; \\
\text { Daerah } \\
\text { Sepanjang } \\
\text { Kapal }\end{array}$ & $\begin{array}{c}\text { Rata-rata } \\
\text { Beban } \\
\text { Rancangan } \\
\text { Kapal } \\
\left\{\mathrm{kN} / \mathrm{m}^{2}\right\}\end{array}$ & $\begin{array}{c}\text { Perbedaan Rata- } \\
\text { rata dari Rerata } \\
\text { Beban Rancangan } \\
\text { Kapal }\end{array}$ \\
\hline 1. & $\begin{array}{l}\text { Rata-rata } \\
\text { beban } \\
\text { rancangan } \\
\text { geladak } \\
\text { kapal }\left(\mathrm{P}_{\mathrm{D}}\right) \\
\mathrm{P}_{\mathrm{D}}= \\
\left\{\mathrm{kN} / \mathrm{m}^{2}\right\}\end{array}$ & 107,851 & $\begin{array}{l}\frac{(107,851-110,945)}{110,945} \times \\
100 \% \\
=-2,788 \%\end{array}$ \\
\hline 2. & $\begin{array}{l}\text { Rata-rata } \\
\text { beban } \\
\text { rancangan } \\
\text { dasar kapal } \\
\left(\mathrm{P}_{\mathrm{B}}\right) \\
\end{array}$ & 126,515 & $\begin{array}{l}\frac{(126,515-110,945)}{110,945} \mathrm{X} \\
100 \% \\
=14,033 \%\end{array}$ \\
\hline
\end{tabular}
Load) Sisi Kapal

Tabel 9. Rata-rata Beban Rancangan Kapal: 


\begin{tabular}{|c|c|c|c|}
\hline & $P_{B}=\left\{k N / m^{2}\right\}$ & & \\
\hline 3. & $\begin{array}{l}\text { Rata-rata } \\
\text { beban } \\
\text { rancangan } \\
\text { sisi kapal } \\
\left(\mathrm{P}_{\mathrm{S}}\right) \\
\mathrm{P}_{\mathrm{S}}= \\
\left\{\mathrm{kN} / \mathrm{m}^{2}\right\}\end{array}$ & 98,471 & $\begin{array}{l}\frac{(98,471-110,945)}{110,945} \mathrm{x} \\
100 \% \\
=-11,243 \%\end{array}$ \\
\hline 4. & $\begin{array}{l}\text { Rata-rata } \\
\text { dari rerata } \\
\text { beban } \\
\text { rancangan }\end{array}$ & $\sum=332,837$ & $\sum / 3=110,945$ \\
\hline
\end{tabular}

\section{Kesimpulan:}

1. Hasil perhitungan beban rancangan (design load) kapal dipengaruhi oleh beberapa faktor seperti ; gaya dari dalam kapal, gaya dari luar kapal, jenis kapal, panjang kapal, perbandingan ukuran utama, gelombang air laut, dan korosi baja baja.

2. Dalam perhitungan beban rancangan konstruksi kapal dipilih kapal barang umum dengan ukuran utama sebagai berikut ; Loa $=131,273 \mathrm{~m}, \mathrm{Lpp}=122$, $360 \mathrm{~m}, \mathrm{~B}=19,50 \mathrm{~m}, \mathrm{H}=11,138 \mathrm{~m}, \mathrm{~T}=$ $8,77 \mathrm{~m}, \mathrm{Cb}=0,74$, dwt $=12.000$ tons, displacement $=15.875$ tons, speed $=13$ knots, $\mathrm{Cm}=0,98, \mathrm{Cw}=0,83, \mathrm{ME}=6.700$ hp.

3. Beban rancangan (design load) dari $\mathrm{P}_{\mathrm{D}}$, $\mathrm{P}_{\mathrm{B}}$, maupun $\mathrm{P}_{\mathrm{S}}$ menjadi faktor parameter dalam perhitungan konstruski kapal.

4. Hasil perhitungan dari beban rancangan adalah sebagai berikut ; Beban rancangan geladak cuaca $\left(\mathrm{P}_{\mathrm{D}}\right)$; rata-rata $\mathrm{P}_{\mathrm{D}}=$ $107,851 \mathrm{kN} / \mathrm{m}^{2}, \mathrm{P}_{\mathrm{D}}$ daerah buritan $=9,99$ $\%$ lebih besar dari $\mathrm{P}_{\mathrm{D}}$ tengah kapal, karena bangunan atas seperti poop deck, bridge deck, navigation deck, dan wheel house disangga oleh pelat geladak bagian buritan

5. Beban rancangan $\mathrm{P}_{\mathrm{D}}$ daerah haluan $=64$, $00 \%$ lebih besar dari $\mathrm{P}_{\mathrm{D}}$ daerah tengah kapal, karena jarak pelat geladak daerah haluan dengan geladak akil maupun mesin jangkar berdekatan satu sama lainnya, dan pelat geladak bagian haluan menyangga keduanya.

6. Beban rancangan dasar kapal $\left(\mathrm{P}_{\mathrm{B}}\right)$ adalah sebagai berikut ; rata-rata $P_{B}=126,515$
$\mathrm{kN} / \mathrm{m}^{2}, \mathrm{P}_{\mathrm{B}}$ daerah buritan $=13,93 \%$ lebih besar dari $\mathrm{P}_{\mathrm{B}}$ daerah tengah kapal, karena letak pelat dasar bagian buritan dengan kamar mesin, baling-baling, maupun kemudi berdekatan satu sama lainnya, sebab lainnya adalah pelat dasar bagian buritan dapat meredam getaran dari mesin utama, getaran dari balingbaling, maupun getaran dari kemudi.

7. $\mathrm{P}_{\mathrm{B}}$ daerah haluan $=64,00 \%$ lebih besar dari $\mathrm{P}_{\mathrm{D}}$ daerah tengah kapal, karena sebagian dari pelat dasar bagian haluan menjadi pelat linggi haluan, dimana pelat linggi haluan selalu dihantam gelombang air laut pada saat kapal berlayar.

8. Beban rancangan sisi kapal $\left(\mathrm{P}_{\mathrm{S}}\right)$ adalah ; rata-rata $P_{S}=98,471 \mathrm{kN} / \mathrm{m}^{2}, P_{S}$ daerah buritan $=11,53 \%$ lebih besar dari $\mathrm{P}_{\mathrm{S}}$ daerah tengah kapal, dan $\mathrm{P}_{\mathrm{S}}$ daeran haluan 20, $80 \%$ lebih besar dari $\mathrm{P}_{\mathrm{S}}$ daerah tegah kapal, alasan keduanya sama dengan $\mathrm{P}_{\mathrm{D}}$ maupun $\mathrm{P}_{\mathrm{B}}$

9. Rata-rata $P_{B}$ lebih besar dari rata-rata $P_{D}$ maupun $P_{S}$, perbedaan rata-rata nilai tersebut disebabkan oleh faktor korosi baja dan faktor gelombang air laut.

10. Rata-rata nilai $P_{S}$ lebih kecil dari rata-rata $\mathrm{P}_{\mathrm{D}}$ maupun $\mathrm{P}_{\mathrm{B}}$, perbedaan rata-rata nilai tersebut disebabkan oleh jarak antara pelat sisi dengan sumbu netral memanjang kapal berdekatan satu sama lainnya.

\section{Daftar Pustaka}

Biro Klasifikasi Indonesia, Peraturan Klasifikasi Konstruksi Kapal Laut Baja, Peraturan Lambung, 2004.

Biro Klasifikasi Indonesia, Peraturan Klasifikasi Konstruksi Kapal Laut Baja, Peraturan Lambung, 2006.

Biro Klasifikasi Indonesia, Rules For The Clasification And Construction Of Seagoing Steel Ships, Rules For Hull Volume II, 2009.

I Gusti Made Santoso, Teori Bangunan Kapal, Departemen Pendidikan dan Kebudayaan, 1983

Lawrence H. Van Vlack, Ilmu dan Teknologi Bahan, Erlangga, Jakarta, 1995 
Muhammad Mahfud, Konstruksi kapal I, Poltek Perkapalan ITS, 1994.

R.C. Hibbeler, Mekanika Teknik, Statika, Prenhalindo, Jakarta, 1997

Schiffbau Technisches Handbuch, 2 Auflage, Band 1, W. Henschke, Vebverlag Technik, Berlin, 1957.

Taggart R, Ship Design Construction, SNAME, 1980

Wasono, Kamus Istilah Teknik Kapal dan Industri Kapal, IPERINDO, 2005 